\title{
INTEGRATING EXPENDITURE AND TAX DECISIONS: \\ THE MARGINAL COST OF FUNDS AND THE MARGINAL BENEFIT OF PROJECTS
}

\author{
Joel Slemrod \\ Shlomo Yitzhaki \\ Working Paper 8196 \\ http://www.nber.org/papers/w8196 \\ NATIONAL BUREAU OF ECONOMIC RESEARCH \\ 1050 Massachusetts Avenue \\ Cambridge, MA 02138 \\ March 2001
}

We would like to thank Louis Kaplow and Stanley Winer, the editor and two anonymous referees for perceptive comments on earlier drafts. The views expressed herein are those of the authors and not necessarily those of the National Bureau of Economic Research.

C 2001 by Joel Slemrod and Shlomo Yitzhaki. All rights reserved. Short sections of text, not to exceed two paragraphs, may be quoted without explicit permission provided that full credit, including $\odot$ notice, is given to the source. 
Integrating Expenditure and Tax Decisions:

The Marginal Cost of Funds and the Marginal Benefit of Projects

Joel Slemrod and Shlomo Yitzhaki

NBER Working Paper No. 8196

March 2001

JEL No. H21, H41, H43

\begin{abstract}
This paper seeks to clarify the extent to which the rule for providing public goods ought to correct for the distortionary cost of raising funds. We argue that, in evaluating public projects, the marginal cost of funds (MCF) concept must be supplemented by a symmetrical concept, which we label the marginal benefit of public projects, or MBP, which indicates the value to individuals of the dollars spent. Each of these concepts can be decomposed into two separate components, one reflecting efficiency and the other characterizing the distributional impact of the project itself or its financing. We conclude that efficiency of the financing cannot be ignored, that distributional considerations are also relevant, and that the availability and optimality of tax instruments is critical for evaluating the appropriateness of proceeding with a public good-cum financing project. However, one can construct special cases, as in Kaplow (1996), where the simple cost-benefit criterion applies.
\end{abstract}

Joel Slemrod

Office of Tax Policy Research University of Michigan Business School

701 Tappan Street, Rm. A2120

Ann Arbor, MI 48109-1234

Email: jslemrod@umich.edu
Shlomo Yitzhaki

Department of Economics

Hebrew University

Jerusalem, 91905

Israel

msruhama@mscc.huji.ac.il 


\section{Integrating Expenditure and Tax Decisions:}

\section{The Marginal Cost of Funds and the Marginal Benefit of Projects}

\section{Introduction}

In their classic textbook, Musgrave and Musgrave (1989) lament the disconnection between the expenditure and tax sides of public finance: "Although good economic analysis calls for joint consideration of both aspects, the practice is to deal with them separately." (p. 211) One notable exception to this disconnection is the issue of to what extent an analysis of public goods ought to correct for the distortionary cost of raising the funds for the project. Pigou (1947) discusses the subject, and the modern analytical treatment of the subject is well illustrated by Atkinson and Stern (1974), who derive the tax-modified Samuelson rule for public good provision and the "marginal cost of funds" henceforth (MCF). Much recent work has extended this analysis, but apparent contradictions remain. For example, Kaplow (1996) argues that the decision about whether to provide a public good should be made without taking into account the marginal welfare cost of taxation and that it is optimal to supply the public good when the "simple cost-benefit test is satisfied." This surprising result apparently contradicts Atkinson and Stern (1974) as well as a long line of literature using distributional weights in evaluating public goods (e.g., Harberger (1978, 1980), Squire (1980), Brent (1984)).

The aim of this paper is to generalize this literature and, in so doing, clarify the recent contributions. The generalization includes allowing for evasion, avoidance, and administrative costs of taxation. We maintain that the concept of MCF should continue to serve as the basic rule for evaluating the revenue side. However, in evaluating public 
projects, the MCF concept should be supplemented by a symmetrical concept, which we will refer to as the Marginal Benefit from Public projects, hereafter MBP, which indicates the value to the individuals in the community of a dollar spent on a public project. The calculations of cost-benefit analysis should compare the MBP to MCF, with a recommendation to accept the project if the MBP is greater than the MCF.

We also argue that, in general, distributional considerations should not be ignored. To directly deal with distributional considerations, the MCF concept is decomposed into two separate components: Marginal Efficiency Costs of public Funds (Mayshar and Yitzhaki (1995), MECF hereafter) and Feldstein's (1972) Distributional Characteristics of the tax base (DC). Similarly, for each parameter affecting the spending on a public project, the MBP can be decomposed into a marginal efficiency benefit of funds (MEBP) and a distributional characteristics of the public good (also DC). The MEBP indicates the (equivalent of) monetary value (i.e., the willingness to pay) to the individuals of spending an additional dollar by the government, and the DC evaluates its effect on social welfare. Finally, we stress the critical importance of the assumptions made about the availability of tax instruments, and whether the tax structure is assumed to be optimal.

The structure of the paper is the following. Section II is devoted to a discussion of the MCF, DC and MECF concepts for a change in one indirect tax, while section III discusses the MBP and MEBP concepts. Section IV extends the analysis to any parameter in the tax law, while Section V applies the arguments to the structure of the linear income tax. Section VI elaborates on optimal public good provision in the presence of a non-optimal tax system. Section VII comments on recent contributions to this literature, in particular Kaplow (1996), in the light of the framework presented here. Section VIII concludes. 


\section{The MCF and MECF Concepts}

We first address the problem in a setting in which avoidance, evasion and administrative costs do not exist, and where the only tax instruments are commodity taxes. It is assumed that the government evaluates its actions with reference to a social welfare function of the following form:

$$
W\left(V^{l}\left(G_{1}, G_{2}, . ., G_{J}, q_{1}, \ldots q_{n}, y_{1}\right), \ldots, V^{H}\left(G_{1}, \ldots, G_{J}, q_{1}, . . q_{n}, y_{H}\right)\right)
$$

where $G_{j}$ is a pure public good $(j=1, . ., J), q_{i}(i=1, \ldots, n)$ is the price of a private good that the consumer faces, and $\mathrm{y}_{\mathrm{h}}$ is the given lump-sum income of individual $\mathrm{h}(\mathrm{h}=1, \ldots, \mathrm{H})$. It is assumed that the vector of producer prices (including wages), $p$, is given and that $t_{i}=q_{i}-$ $\mathrm{p}_{\mathrm{i}}$ are the commodity tax rates. (A non-linear income tax will be introduced at a later stage). Government actions are constrained by the budget constraint (2):

(2) $R_{0}=G-R=\sum_{j=1}^{J} P_{j} G_{j}-\sum_{i=1}^{n} t_{i} X_{i}$,

where $\mathrm{G}$ is total expenditures in the budget and $\mathrm{R}$ is total revenue. The per-unit price of producing $G_{j}$ is $P_{j}$. We use $X_{i}=\Sigma_{h} x_{i}^{h}$ to denote the aggregate quantity (or expenditures in the case of ad valorem taxes) of commodity $\mathrm{i}$, and $\mathrm{x}_{\mathrm{i}}^{\mathrm{h}}$ is the quantity private of good $\mathrm{i}$ consumed by individual $h$.

In what follows we do not assume that the government is at all times maximizing the social welfare function. Instead, we presume only that there exists a particular tax system that satisfies the budget constraint, and that the government is considering increasing tax revenue by $\$ 1$ in order to finance an increase in the supply of a public 
good. The issue at hand is whether the government, which is interested in increasing social welfare, should proceed.

We first consider whether it is social-welfare-increasing to increase the production of $\mathrm{G}_{\mathrm{j}}$ by one dollar and to finance it through an increase in $\mathrm{t}_{\mathrm{i}}$. To evaluate whether this package of expanded public goods with a specified financing scheme is worth proceeding with, one has to compare the increase in social welfare from increasing the supply of the public good to the reduction in the social welfare due to the increase in taxes. Equation (3) presents the comparison:

$$
\frac{\sum_{h=1}^{H} \frac{\partial W}{\partial V^{h}} \frac{\partial V^{h}}{\partial G_{j}} d G_{j}}{\left(P_{j}-\frac{\partial R}{\partial G_{j}}\right) d G_{j}}+\frac{\sum_{h=1}^{H} \frac{\partial W}{\partial V^{h}} \frac{\partial V^{h}}{\partial t_{i}} d t_{i}}{\frac{\partial R}{\partial t_{i}} d t_{i}}(\geq ?<) 0 .
$$

Equation (3) is derived from rearranging the derivatives of the social welfare function (1) and the revenue constraint (2) with respect to both $\mathrm{G}_{\mathrm{j}}$ and $\mathrm{t}_{\mathrm{i}}$. The numerators in both terms of (3) are, respectively, the direct effect of increasing $\mathrm{G}_{\mathrm{j}}$ and the direct effect of increasing $t_{i}$, on social welfare. The dominators represent the impact of increasing $G_{j}$ and the impact of increasing $t_{i}$ on the budget constraint of the government, respectively. Since the budget constraint is given, the denominators are equal to each other. The first term on the left-hand side is the increase in social welfare per (net) dollar spent by the government on $\mathrm{G}_{\mathrm{j}}$. The second term represents the decrease in social welfare per dollar increase in revenue collected through an increase in $t_{i}$. Therefore, the project increases social welfare, and worth pursuing if (3) is positive.

In other words, the first term of equation (3) evaluates, on the margin, the benefit to the society of increasing the production of the public good per dollar of net expenditure by the government. The second term evaluates the cost to the society, at the 
margin, of increasing the tax rate on commodity $i$ that the net revenue received by the government increases by one dollar. This project should proceed if the first term, which we will refer to as the Marginal Benefit from Public Goods (MBP), is greater than the cost to the society of raising the funds necessary to finance the project, hereafter the Marginal Cost of Funds, or MCF.

We next consider more closely the MCF, a concept that has been discussed extensively in the literature. ${ }^{1}$ With producer prices given, and denoting the social evaluation of the marginal utility of income as $\beta^{\mathrm{h}}=\left(\partial \mathrm{W} / \partial \mathrm{V}^{\mathrm{h}}\right)\left(\partial \mathrm{V}^{\mathrm{h}} / \partial \mathrm{y}_{\mathrm{h}}\right)$, then using Roy's identity one can rewrite the right-hand side of equation (3) as:

(4) $\quad M C F_{i}=\frac{X_{i}}{M R_{i}} \sum_{h} \beta^{h} s_{i}^{h}$

where $\mathrm{s}_{\mathrm{i}}{ }^{\mathrm{h}}=\mathrm{x}_{\mathrm{i}}{ }^{\mathrm{h}} / \mathrm{X}_{\mathrm{i}}$ is the share of individual $\mathrm{h}$ in the consumption of commodity $\mathrm{i}$ and $\mathrm{MR}_{\mathrm{i}}$ is the marginal revenue with respect to $\mathrm{t}_{\mathrm{i}}$. Formally, we can write

(5) $\quad M R_{i}=\frac{\partial R}{\partial t_{i}}=X_{i}+\sum_{k=1}^{n} t_{k} \frac{\partial X_{k}}{\partial t_{i}}$.

The right-hand side of (4) can be decomposed into two terms. The first term is defined as

$$
D C_{i}=\Sigma_{h} \beta^{h} s_{i}^{h}
$$

which is Feldstein's (1972) "Distributional Characteristics" of a commodity, and is a weighted average of the social evaluation of the marginal utility of income, weighted by the share of each individual in the burden of raising the tax revenue. It describes the incidence of a dollar burden of taxes, raised through the change in $t_{i}$. The higher is $\mathrm{DC}_{\mathrm{i}}$, the less progressive is the change in the tax on commodity $i$.

\footnotetext{
${ }^{1}$ The derivation of the MCF, and the MECF discussed later, is based on Slemrod and Yitzhaki (1996), who rely on Mayshar (1990) Wildasin (1984), and Mayshar and Yitzhaki (1995).
} 
The second term on the right-hand side is characterized in Mayshar and Yitzhaki (1995) as the Marginal Efficiency Costs of Funds, or MECF, where

(7) $M E C F_{i}=\frac{X_{i}}{M R_{i}}=\frac{X_{i}}{X_{i}+\sum_{k=1}^{n} t_{k} \frac{\partial X_{k}}{\partial t_{i}}}$,

An extended interpretation of the MECF is given in Slemrod and Yitzhaki (1996). Briefly, the MECF measures the ratio of the cost to taxpayers of funds raised to the value of the funds received by the government, ignoring distributional issues. The difference in value between the numerator and denominator is caused by leakages (as in Okun's (1975) "leaky bucket") from the tax base caused by taxpayers that are maximizing utility in the presence of taxation. The direct burden on taxpayers of increasing $t_{i} i_{i}$. At the other end of the transfer, the government receives only $\mathrm{MR}_{\mathrm{i}}$, and the $\mathrm{MECF}_{\mathrm{i}}$ is the ratio of the burden on the individuals to the dollar amount collected by the government.

If $t_{i}$ is a lump-sum levy, and all other tax rates are equal to zero, then the MECF equals one. But in general, as pointed out in Mayshar (1991), when the starting point is an arbitrary tax system, then the MECF of a lump-sum levy can be lower or higher than one. $^{2}$ As discussed in Slemrod and Yitzhaki (1996), one needs only to be able to forecast the revenue generated from a change in each tax rate to calculate the MECF. Combining equations (4), (5) and (6) we have shown that the right-hand side of (3) can be restated as

$$
M C F_{i}=D C_{i} M E C F_{i}
$$

The first term reflects the distributional impact of raising funds via an increase in $t_{i}$, while the second reflects the efficiency costs of raising the funds.

\footnotetext{
${ }^{2}$ A negative value of the MECF indicates that the tax system is on the declining portion of the Laffer curve.
} 
Although a value of one for the MECF has a natural interpretation, this is not true for the MCF unless $\beta^{\mathrm{h}}$ is somehow normalized. For example, Atkinson and Stiglitz (1980) normalize by setting the unweighted mean value of $\beta^{\text {h }}$ to one. Another possibility is to set $\sup _{\mathrm{h}}\left(\beta^{\mathrm{h}}\right)$ to one, which implies that $1 \geq \beta^{\mathrm{h}}>0$, with $\beta^{\mathrm{h}}$ being one for the poorest person. The type of normalization used affects the value of the MCF, but does not affect the decision of whether to approve a public project.

Slemrod and Yitzhaki (1996) defines the MECF in a more complicated setting that includes avoidance activity, evasion and administrative costs. This same setting can be repeated here. However, instead of redeveloping it here we will only explain the logic and the interested reader is referred to the above mentioned paper. In the more general setting, the numerator of equation (7) is the additional tax that would have been collected if there were no behavioral response on behalf of the taxpayer. This tax represents the additional burden on the taxpayer imposed by the changes in the parameters in the tax system. The denominator is the additional tax collected by the government, taking into account the behavioral response. The ratio of the two is the additional burden per additional dollar collected.

The ratio of the tax that would have been collected to the actual additional tax collected is the MECF. To derive this interpretation, note that the difference between the numerator and the denominator is the result of the substitution effect. Assuming that the taxpayer is at an interior solution and that the change in the tax rate is small, it is easy to see that, on the margin, a taxpayer will be ready to sacrifice a dollar value of utility to save a dollar of taxes. Hence, the numerator represents the burden on the taxpayer (which is composed of additional tax collected plus taxes avoided by substitution) while the denominator represents additional tax collected. 
Extending this logic to include evasion and avoidance opportunities as well as administrative costs leads to the following expression:

(7') $\quad M E C F_{i}=\frac{\gamma\left(X_{i}-M R_{i}\right)+C_{i}+M R_{i}}{M R_{i}-A_{i}}$

where $\gamma$ is the social evaluation of the dollars that the taxpayer is sacrificing at the margin in order to save a dollar of $\operatorname{tax}^{3}, C_{i}$ is the marginal compliance cost associated with the change in the ith instrument, $A_{i}$ is the marginal administrative costs, and $M R_{i}-A_{i}$ is the net revenue collected at the margin. The intuitive interpretation of the expression is the same as before, with some qualifications. The potential tax is $\mathrm{X}_{\mathrm{i}},\left(\mathrm{X}_{\mathrm{i}}-\mathrm{MR}_{\mathrm{i}}\right)$ is leaked at a social cost of $\gamma$ per dollar, $\mathrm{MR}_{\mathrm{i}}$ is collected by the government, and $\mathrm{C}_{\mathrm{i}}$ is the additional involuntary compliance cost. Hence, the total burden on society is the sum of those (X and C) components. Of the $\mathrm{MR}_{\mathrm{i}}$ collected by the government, $\mathrm{A}_{\mathrm{i}}$ is spent on administration, leaving $\mathrm{MR}_{\mathrm{i}}-\mathrm{A}_{\mathrm{i}}$ in the coffers. MECF is the burden on society divided by what is collected net of the cost of doing business. This yields the marginal efficiency cost of a dollar collected.

The extension of the analysis into changing several tax rates is also straightforward. The MECF of a change in several tax rates is the weighted average of the MECF of individual tax rates weighted by their share in the revenue raised. ${ }^{4}$

\section{The MBP and MEBP Concepts}

\footnotetext{
${ }^{3}$ The value of dollar saved can be less than a dollar if the taxpayer is at a corner solution. As an example of being in a corner solution, consider the case of a taxpayer who evades all his income.

${ }^{4}$ For a derivation of this result, see Slemrod and Yitzhaki (1996).
} 
We turn next to the first term on the left-hand side of (3), which pertains to the value to the society of a (net) dollar spent by the government on a public good. We show that a decomposition similar to the one applied earlier to the MCF, is useful in interpreting the decision to invest in a public good. Let $\mathrm{b}_{\mathrm{j}}^{\mathrm{h}}=\mathrm{V}_{\mathrm{Gj}}^{\mathrm{h}} / \mathrm{V}_{\mathrm{y}}^{\mathrm{h}}$ be the willingness to pay of individual h for public good $\mathrm{G}_{\mathrm{j}}$, expressed in terms of lump-sum income. ${ }^{5}$

Following the same procedure used for the derivation of the MCF, we can rewrite the left-hand side of equation (3) as:

$$
M B P_{j}=D C_{j} M E B P_{j}, \text { where }
$$

$$
M E B P_{j}=B_{j} /\left(P_{j}-\Sigma_{i} t_{i}\left(\partial X_{i} / \partial G_{j}\right)\right)
$$

In expression (9), DC $C_{j}=\Sigma_{h} \beta^{h} s_{j}^{h}, s_{j}^{h}=b_{j}^{h} / B_{j}$, and $B_{j}=\Sigma_{h} b_{j}^{h}$. In words, $B_{j}$ is the aggregate benefits (willingness to pay) in the society from increasing the public good $\mathrm{G}_{\mathrm{j}}$ by one dollar, and $\mathrm{s}_{\mathrm{j}}^{\mathrm{h}}$ is the share of individual $\mathrm{h}$ in the aggregate benefits. The MEBP is the ratio of the (equivalent) of monetary benefits to the individuals to the dollars spent by the government. The distributional characteristic $\mathrm{DC}_{\mathrm{j}}$ describes the distribution of the benefits among the population. For a given sum of willingness to pay, the larger the effect on those with higher social marginal utility of income, the higher the DC of the public good. This is because the higher the marginal utility of the individual, the higher

\footnotetext{
${ }^{5}$ If free disposal exists, then the relevant willingness to pay is Max $\left[0, b_{j}{ }^{h}\right]$. If free disposal is not allowed then $b_{j}^{h}$ may be negative and it will represent the willingness to pay to get rid of $G_{j}$.
} 
will be the distributional characteristic parameter for a given sum of $b_{j}^{h}$. Note that the MEBP is formally similar to the MECF, because both refer to the ratio of direct costs or benefits to individuals to the (net) cost to the government.

If the public good has no effect on tax revenue, then $\mathrm{MBP}_{j}=\mathrm{DC}_{\mathrm{j}}\left(\mathrm{B}_{\mathrm{j}} / \mathrm{P}_{\mathrm{j}}\right)$. This implies that the MEBP of a public good depends both on its revenue effect and on the intrinsic value of the public good, and suggests that the $\mathrm{MEBP}_{\mathrm{j}}$ can be further decomposed as

$$
M E B P_{j}=\left(B_{j} / P_{j}\right) *\left(1 /\left(1-\Sigma_{i}\left(t_{i} / P_{j}\right) *\left(\partial X_{i} / \partial G_{j}\right)\right) \equiv\left(B_{j} / P_{j}\right) * M R C P_{j} .\right.
$$

The $\left(\mathrm{B}_{\mathrm{j}} / \mathrm{P}_{\mathrm{j}}\right)$ term measures the ratio between the value to the individuals of the public good and the cost to the government. The $\mathrm{MRCP}_{\mathrm{j}}$ (the Marginal Revenue Cost of Public projects) term measures the cost (or benefit) of a public good due to its effect on tax revenues.

Using the decompositions of MCF and MBP, we can now rewrite (3) as follows, implying that a public project is worth doing if

$$
D C_{j}\left(B_{j} / P_{j}\right)\left(M R C P_{j}\right)>D C_{i} M E C F_{i} .
$$

It is instructive to note the formal similarity between the MBP and the MCF, the only difference being that in the former the willingness to pay substitutes for the quantity consumed. Imposing a tax (subsidy) is similar to reducing (increasing) the production of a public good: in both cases the government affects all individuals through a change in a price or in a quantity. The change in the public good changes the welfare of the 
individuals by their willingness to pay, without affecting the prices the individuals face while the change in the tax affects the prices. Roy's identity, which connects the willingness to pay with the marginal utility of income, is responsible for the similarity. ${ }^{6}$

The extension of the analysis to changing the provision of several public goods simultaneously is similar to the extension on the tax side to multiple tax instruments.

\section{Other Tax Instruments}

So far we have considered a tax system which has only commodity taxes as tax instruments. However, it is important to note that the analytical structure involving the $\mathrm{MCF}$ and MBP is quite general, and can be applied to any parameter that affects the tax system. It can be extended, for example, to parameters of the tax enforcement system, such as the fraction of tax returns that are audited. It can include a uniform lump-sum tax or a differential lump-sum tax. It can deal with complicated tax structures such as those that characterize the income tax, including such features as allowances, exemptions, and income brackets. Each parameter is treated in a similar way as any commodity tax in the earlier model.

To see the generality of the approach, consider any tax instrument z. In order to evaluate its MCF, one has to know its direct impact on social welfare, plus its impact on

\footnotetext{
${ }^{6}$ Note that, because the social welfare function affects only the distributional characteristics, the MECF and the MEBP are still useful for a government with an objective other than maximizing social welfare. For example, if the government is a maximizer of votes (Hettich and Winer $(1997,1999$, ch. 6)), so that the target function is $\mathrm{P}\left(\mathrm{U}^{1}(), \ldots \mathrm{U}^{\mathrm{H}}()\right)$ is the probability of voting for the government as a function of the utility level of the individuals, then all we have to do to adapt our concepts is to substitute "voting characteristics" for distributional characteristics which will be a weighted average of the government evaluation of the change in probability to vote for the government of the h-th individual weighted by the burden imposed on him. That is, instead of $\beta^{\mathrm{h}}=\left(\partial \mathrm{W} / \partial \mathrm{v}^{\mathrm{h}}\right)\left(\partial \mathrm{v}^{\mathrm{h}} / \partial \mathrm{y}\right)$, one can use $\beta_{\mathrm{h}}^{*}=\left(\partial \mathrm{P} / \partial \mathrm{U}^{\mathrm{h}}\right)\left(\partial \mathrm{U}^{\mathrm{h}} / \partial \mathrm{y}\right)$ in the definition of the DC of the commodity.
} 
tax revenue. The MCF is simply the ratio of the former to the latter. In expression (4) and thereafter, $\mathrm{X}$ refers no longer to the amount of good $\mathrm{X}$ consumed, but rather to the tax base to which instrument $\mathrm{z}$ applies. It reveals the amount of revenue that would be collected from a change in $\mathrm{z}$, absent any behavioral response. The effect on the social welfare function can be further decomposed into the distributional characteristic and the Marginal Efficiency Cost of Funds components. This procedure is relevant to every parameter $\mathrm{z}$, be it a marginal tax rate, an income bracket or any other parameter. For example, it can be shown that in the context of an income tax, expression (7) reduces to $1 /(1-\mathrm{e})$, where e (defined to be a positive number) is the elasticity of taxable income. This concept is discussed in Feldstein (1997) and Slemrod (1998).

The introduction of a general non-linear income tax, can be interpreted in the case of a continuous distribution of endowments as introducing an infinite number of tax parameters, or in the case of a discrete distribution of endowments as introducing a number of parameters at least as large as the number of individuals, with each marginal tax rate being a separate tax parameter. The DC of each marginal tax rate is calculated as if it was a lump-sum tax on all incomes higher than the income on which the marginal tax is effective. The MECF is determined by the change in tax revenue of all taxpayers with income equal or higher than the one on which the marginal tax is imposed.

A final, important, example arises if the government is able to charge each individual according to his willingness to pay for the public good. In this case, $\mathrm{DC}_{\mathrm{j}}=$ $\mathrm{DC}_{\mathrm{i}}$. In this case one can ignore distributional issues because the project (and its financing) is distributionally neutral. If, in addition, MECF equals one, then according to $\left(3^{\prime}\right)$, the project should be done as long as $\mathrm{MEPB}_{\mathrm{j}}$ exceeds one. This corresponds to 
Lindahl's solution to the public good provision problem. We return to this example in Section VII in our discussion of Kaplow (1996).

Before moving on, we pause here to make an important observation. At the margin, whether or not to proceed with a given public good project depends on the financing scheme that accompanies it. It may be sensible to proceed with a given project under one financing scheme, but not with another.

\section{Optimal Tax Systems and Optimal Public Good Provision}

To this point we have not assumed that, when considering whether to undertake a public good-cum-financing package, the existing tax system is any sense optimal. We now turn to consider how this would change our analysis.

An optimal tax system is that structure which maximizes (1), subject to (2), over the set of available tax instruments, holding the vector of public goods fixed. For some instruments, such as commodity taxes, there is no constraint on the value of the tax rate: a negative tax is simply a subsidy. In other cases, such as the amount of resources devoted to auditing, a negative setting is not feasible, so there is a non-negativity constraint.

It is straightforward to show that in the optimal tax structure all tax instruments that are utilized have an equal value of $\mathrm{MCF}_{\mathrm{i}}=\mathrm{DC}_{\mathrm{i}} * \mathrm{MECF}_{\mathrm{i}}$. To illustrate the implications of this, we consider the problem analyzed by Wilson (1991) and Sandmo (1998), in which the government has only two tax instruments: a uniform lump-sum tax 
(or demogrant), and a single marginal income tax. Assume that the linear income tax can be characterized as

$$
T=a+t w L,
$$

with w being the wage rate while $\mathrm{L}$ is hours worked. Assume that there is a zero revenue requirement. Then, the linear tax may have two possible structures: $(a>0$ and $t<0)$ where the tax is composed of a lump-sum tax and a subsidy for labor income, or $(\mathrm{a}<0$ and $t>0$ ), that is, a lump-sum subsidy and a positive tax rate. We will consider only the second structure because, as shown later, the first can never be optimal. Let $\mathrm{DC}_{\mathrm{a}}$ be the distributional characteristic of the lump-sum tax. ${ }^{7}$ Then

(13) $D C_{a}=(1 / H) \Sigma_{h} \beta^{h}$ and

(14) $D C_{t}=\Sigma_{h} s^{h} \beta^{h}$,

where $s^{h}=\left(w_{h} L_{h}\right) /\left(\sum_{h} w_{h} L_{h}\right)$ is the share of individual $h$ in labor income and $(1 / H)$ is effectively the share of each individual $h$ in an equal per-capita head tax. The MECF's are

\footnotetext{
${ }^{7}$ Note that $\mathrm{DC}_{\mathrm{a}}$ and $\mathrm{MECF}_{\mathrm{a}}$ refer to the distributional characteristic and cost of funds of raising revenue via increasing a.
} 


$$
\operatorname{MECF}_{a}=\frac{1}{1+t \sum_{h=1}^{n} w_{h} \frac{\partial L_{h}}{\partial a}}
$$

and

$$
M E C F_{t}=\frac{\sum_{h} w_{h} L_{h}}{\sum_{h} w_{h} L_{h}+t \sum_{h} w_{h} \frac{\partial L_{h}}{\partial t}} .
$$

We first show that, provided that the social evaluation of the marginal utility of income declines with labor income, then

$$
D C_{a}-D C_{t}=\Sigma_{h} \beta^{h}\left(1 / H-s^{h}\right)>0
$$

To see that expression (17) is positive, arrange the population in declining order of $\beta$. (By assumption, this will also be in increasing order of labor income). Since $\mathrm{s}^{\mathrm{h}}$ increases with $h$, it must be that the term in brackets decreases with $h$. Since, by definition, $\Sigma_{\mathrm{h}}(1 / \mathrm{H}$ $\left.-s^{h}\right)$ is zero, it must be that the term in the brackets is positive for small h, and negative for large $h$. Since $\beta^{h}$ is positive and declines with $h$, it follows that $D C_{a}-D C_{t}>0$, and so $\mathrm{DC}_{\mathrm{a}}>\mathrm{DC}_{\mathrm{t}}$. If these two instruments are used optimally, then $\mathrm{DC}_{\mathrm{a}} * \mathrm{MECF}_{\mathrm{a}}=$ $\mathrm{DC}_{\mathrm{t}} * \mathrm{MECF}_{\mathrm{t}}$, so that $\mathrm{MECF}_{\mathrm{t}}>\mathrm{MECF}_{\mathrm{a}}$. If, on average, leisure is a normal good (i.e., $\left.\Sigma_{h} W_{h}\left(\partial L_{h} / \partial a\right)>0\right)$, then $\mathrm{MECF}_{\mathrm{a}} \leq 1$; thus, $\mathrm{MECF}_{\mathrm{a}}$ differs from one (only) because of income effects.

Note that, when the tax system is optimal, the choice of whether at the margin to proceed with a public good project does not depend on any assumed financing scheme, because within the set of feasible taxes all schemes have the same MCF. ${ }^{8}$ In this case one can speak of "the" marginal cost of funds that can be used as a benchmark for any

\footnotetext{
${ }^{8}$ This is in sharp contrast to the rule that applies when the tax system is not optimal, when project approval should depend on what financing package accompanies the project.
} 
prospective public good project. Although different alternative financing schemes will in general have different values of MECF, each tax instrument used will have an offsetting value of the DC. The less "efficient" instruments used, i.e., those with a high value of the MECF, will necessarily also have a low value of the DC - they will raise revenue from individuals with relatively low social marginal valuations. ${ }^{9}$

Mirrlees' (1971) optimal non-linear income tax problem is another example of optimization. As mentioned in Section IV, one can view Mirrlees' income tax problem as having an infinite number of instruments. If the income tax is set to be optimal, then the MCF of each of the infinite number of tax parameters must be equal. The solution to this problem is complicated, inter alia, because of the simultaneous impact of those marginal tax rates on the MECF of each other.

In parallel to considering an optimal tax system, one can consider the case in which the set of public goods is optimized, for a given amount of funds that may or may not have been raised optimally. If no projects are lumpy, then it is straightforward to show that at the optimum all projects undertaken will have the same value of $\mathrm{MBP}=$ $\mathrm{DC}^{*}(\mathrm{~B} / \mathrm{P})^{*}(\mathrm{MRCP})$. Those projects that fail to meet this common value are not undertaken. Although there is one common value of the MBP, any marginal project is more likely to be accepted the "better" is the financing package that accompanies it, where better means a lower value of the MCF.

If the set and quantity of both public goods and tax instruments can be chosen optimally, then all tax instruments used will have the same value of MCF $=\mathrm{DC} * \mathrm{MECF}$, and all the public goods provided will have the same value of $\mathrm{MBP}=\mathrm{DC} *(\mathrm{~B} / \mathrm{P})^{*} \mathrm{MRCP}$. Furthermore, the common value of the MCF will equal the common value of the MBP.

\footnotetext{
${ }^{9}$ Condition (17) can be used to show that the case $(\mathrm{a}>0, \mathrm{t}<0)$ cannot be optimal.
} 


\section{Optimal Public Good Provision in the Presence of a Non-Optimal Tax System}

Assuming that taxes are set optimally is convenient, because it allows us to assume that the MCF's are equal. It is, though, implausible that these conditions are met in practice. On the other hand, when the starting point is non-optimal, each tax parameter in the system may be associated with a different MCF. This implies that associating a project with one set of taxes may suggest that it be rejected, while associating it with another set of taxes may suggest that it be accepted. In this situation understanding why the existing tax system is not optimal becomes important. In what follows we consider three types of explanations: (a) There has been a change in the parameters of the problem since the last time the tax/public expenditure system was reformed. (b) There are other (e.g., political) constraints that have not been addressed in the model. (c) There exist nonconvexities or discontinuities in the administrative cost function.

If a change in parameters is the culprit, the first-best response is to reform the tax system in order to return it to an optimal setting. A relatively low MCF does not justify accepting a project, nor does a relatively high MCF justify not accepting it.

If the culprit is outside-the-model constraints, the MCFs redefined to include the shadow prices for these constraints would again all be equal. Because the shadow prices may affect different MCFs differently, the MCFs calculated ignoring these extra-model constraints may differ. For example, assume that the MCF of eliminating the mortgage interest deduction is relatively low, but the (unmeasured) political cost of eliminating it is substantial. Then, applying the MCF of this impossible-to-implement tax instrument could justify many projects that could not be justified if coupled with other, feasible, tax instruments. How should a policy maker proceed in this case? Assuming that it is 
certainly feasible to raise additional taxes by proportionally raising all existing tax rates, one can use an average of these MCFs, weighted by their marginal tax revenue, as a rule of thumb for the MCF for project evaluation.

Finally, consider the point emphasized in Slemrod and Yitzhaki (1996), that administrative costs tend to be discontinuous and non-convex. For example, introducing a value added tax will entail a large fixed cost, as a process of reporting and monitoring the tax base of each firm must be established. Having this infrastructure in place lowers the MECF of further VAT revenue and may also affect the MECF of other tax instruments, e.g., by providing information that is relevant for income tax enforcement. Although the marginal cost of raising the first dollar from a VAT may appear prohibitively high, the marginal cost of raising funds from an existing VAT may be quite low. Now consider a country that does not currently have a VAT, but for which at a slightly higher level of revenue requirement it would make sense to adopt a VAT to raise a substantial fraction of its revenues. For deciding whether to proceed with a public project funded by VAT, it is not appropriate to use the literal marginal cost of raising funds, but instead one should consider the cost of non-discrete changes in the tax system.

These three explanations for unequal MCFs have different policy implications. To see this, let us ignore distributional issues and assume a representative consumer economy, so that we can state the issue in terms of the MECF instead of the MCF. Consider the example where the MECF of a specific funding alternative is less than one. This implies that a public project may be adopted even if the marginal benefit of the project is equal to or lower than one or, loosely speaking, its return is negative; this is because a "cheap" way of raising public funds has been identified. 
Under a reformed, optimal, tax system the MECF of this--and any other--funding method must be greater than one. ${ }^{10}$ Thus, the right solution is to reform the system and not to adopt the "MEBP $<=1$ " project. If, on the other hand, there are adminstrative cost non-convexities, then it may appropriate to adopt this project because the tax system is in a neighborhood of a (locally) low marginal cost of raising funds. Finally, if there are unmodeled constraints, then a weighted average MECF of certainly feasible tax instruments may be an appropriate benchmark for evaluating projects.

\section{Relationship to Recent Literature}

Sandmo (1998) addresses similar issues, and reaches conclusions which are compatible with those stated here. However, our approach is more general than Sandmo's on a number of dimensions. First, we allow a general social welfare function, while Sandmo treats only a utilitarian social objective function. Second, our methodology allows for a wider range of behavioral response, including for example avoidance and evasion, and a wider set of instruments. Finally, we stress the parallel nature of the optimal taxation and optimal public good provision problems. Sandmo, on the other hand, does not restrict the analysis to the margin.

$\mathrm{Ng}(2000,259)$ informally makes a similar point to ours in his reconciliation of Feldstein (1997) and Kaplow (1996). He argues that one must consider the incentive effects of both the public spending and the accompanying tax, and the net distributional

\footnotetext{
${ }^{10}$ This will obtain in the absence of the kind of non-convexities discussed above. As demonstrated in Yitzhaki (1979), in this case the MECF must always be above one.
} 
effect of the package. He does not, though, develop an analytical framework for assessing whether to undertake a package of public spending and funding.

Our analysis is completely consistent with the tone of Kaplow (1996), but it is inconsistent with its central conclusion. The tone of Kaplow's paper is well captured by the following statement: "Knowledge that the aggregate reform -- the public good and the tax adjustment, taken together -- causes distortion thus provides little guidance, because the existence of distortion is associated with greater redistribution." (p. 520) This is completely consistent with the analysis presented here. In terms of expression $\left(3^{\prime}\right)$, knowing the terms that have to do with revenue leakage and therefore efficiency, MECF and MRCP, is not sufficient for deciding whether to proceed with a public good; $\mathrm{DC}_{\mathrm{j}}$ and $\mathrm{DC}_{\mathrm{i}}$, the distributional characteristics of the public good and the assumed financing, also enter into the decision.

It does not follow, though, that for any given financing mechanism, expression (3') reduces to $\left(B_{j} / P_{j}\right)>1$, which is what is implied by Kaplow's statement that it is optimal to supply the public good when "the simple cost-benefit test is satisfied." Yes, in general there is a tendency for more progressive tax schemes (those with a low value of $\mathrm{DC}_{\mathrm{i}}$ ) to be more distorting (have a high value of $\mathrm{MECF}_{\mathrm{i}}$ ), and similarly for public goods. But, outside of an optimum, there is no necessary link between the distrbutional characteristic of a tax on public good and the revenue leakage associated with it. Indeed, one can easily imagine tax schemes which are both regressive and inefficient, such as an easily evaded tax on a commodity consumed disproportionately by the poor. Moreover, one can imagine two tax schemes that have identical distributional characteristics but are not equally efficient. It might certainly be appropriate to reject a public good with a 
value of $\left(\mathrm{B}_{\mathrm{j}} / \mathrm{P}_{\mathrm{j}}\right)$ that exceeds one that had to be financed by an inefficient tax, but to accept it if it is financed by an efficient tax.

If one is willing to assume that the initial tax system and the financing package are optimal, then it is correct that the MECF is irrelevant. In this case at the optimum $\mathrm{DC} * \mathrm{MECF}$ is equal for all financing schemes, so the more distorting instruments are necessarily those that cause a more progressive distribution of the burden. Tax instruments, such as those in the example above, which are relatively distorting and not progressive, will not be part of the optimal tax structure.

\section{Conclusion}

In determining whether particular new public projects or changes in the tax system are appropriate, neither the distributional impact of the proposals nor the behavioral response to them should be ignored. This implies that the primitives of the problem, the concavity of the social welfare function, and the magnitude of the behavioral response all affect the evaluation of proposals for financing new public goods. There may, though, be special cases where simpler rules may apply. For example, if the distributional characteristic of the public good is identical to the distributional characteristic of the tax instrument then one can use the simple cost-benefit rule.

Our analysis has focused on marginal increases in public spending. Although marginal evaluations have the advantage of reducing information requirements, one might question the applicability of marginal approximations to discrete projects. In this

paper, the reliance on marginal derivation is necessary to allow for the evaluation of three issues: the willingness to pay, the burden of the change in the tax, and the distributional 
characteristics of the tax and the public project. Our approach is appropriate whenever a first-order approximation does not introduce a large error into the evaluation of the appropriate term. Willig (1976) provides some rules of thumbs for the first two approximations to be reasonable. The third one, concerning the distributional characteristic of the project, requires that the social evaluation of the marginal utility of income is not significantly affected by the project. Further research, along the lines suggested by Willig, might clarify under what conditions this is an appropriate approximation for discrete projects. 


\section{References}

Atkinson, Anthony, and Nicholas Stern. "Pigou, Taxation, and Public Goods." Review of Economic Studies 4 No. 1 (January, 1974): 119-28.

Atkinson, Anthony B., and Joseph E. Stiglitz. Lectures on Public Economics. New York: McGraw-Hill Cook Co., 1980.

Brent, R. J. "Use of Distributional Weights in Cost-Benefit Analysis: A Survey of Schools.” Public Finance Quarterly 12 No. 2 (April, 1984): 213-30.

Dahlby, Bev. "Progressive Taxation and the Social Marginal Cost of Public Funds." Journal of Public Economics 67 No. 1 (January,1998): 105-22.

Feldstein, Martin S. "Distributional Equity and the Optimal Structure of Public Prices." American Economic Review 62 No. 1 (March, 1972): 32-6.

Feldstein, Martin S. "How Big Should Government Be?" National Tax Journal 50 No. 2 (June, 1997): 197-213.

Harberger, Arnold C. "On the Use of Distributional Weights in Social CostBenefit Analysis." Journal of Political Economy 86 No. 2 (April, 1978): S87S120.

Harberger, Arnold C. "Reply to Layard and Squire." Journal of Political Economy 88 No. 5 (October, 1980): 1050-2.

Hettich, Walter, and Stanley L. Winer. "The Political Economy of Taxation." In Perspectives on Public Choice, edited by Dennis C. Mueller. Cambridge: Cambridge University Press, 1997. 
Hettich, Walter, and Stanley L. Winer. Democratic Choice and Taxation. New York: Cambridge University Press, 1999.

Kaplow, Louis. "The Optimal Supply of Public Goods and the Distortionary Cost of Taxation." National Tax Journal 48 No. 4 (December, 1996): 513-33.

Mayshar, Joram. "On Measures of Excess Burden and Their Applications." Journal of Public Economics 43 No. 3 (December, 1990): 263-89.

Mayshar, Joram, and Shlomo Yitzhaki. "Dalton-Improving Tax Reform." American Economic Review 85 No. 4 (September, 1995): 793-807.

Mirrlees, James. "An Exploration in the Theory of Optimum Income Taxation." Review of Economic Studies 38 No. 2 (April, 1971): 175-208.

Musgrave, Richard A., and Peggy B. Musgrave. Public Finance in Theory and Practice. $5^{\text {th }}$ ed. New York: McGraw-Hill Book Company, 1989.

Ng, Yew-Kwang. "The Optimal Size of Public Spending and the Distortionary Cost of Taxation." National Tax Journal 53 No. 2 (June, 2000): 253-72.

Okun, Arthur M. Equity and Efficiency: The Big Trade-off. Washington, D.C.: Brookings Institution, 1975.

Pigou, A. C. A Study in Public Finance. London: MacMillan, 1947.

Sandmo, Agnar. "Redistribution and the Marginal Cost of Public Funds." Journal of Public Economics 70 No. 3 (December, 1998): 365-82.

Slemrod, Joel. "Methodological Issues in Measuring and Interpreting Taxable Income Elasticities." National Tax Journal 49 No. 4 (December, 1998): 773-88. Slemrod, Joel, and Shlomo Yitzhaki. "The Social Cost of Taxation and the Marginal Cost of Funds." International Monetary Fund Staff Papers 43 No. 1 (March, 1996): 172-98. 
Squire, Lyn. "On the Use of Distributional Weights in Social Cost-Benefit Analysis." The Journal of Political Economy 88 No. 5 (October, 1980): 1048-9. Wildasin, David E. "On Public Good Provision with Distortionary Taxation." Economic Inquiry 22 No. 2 (April, 1984): 227-43.

Willig, Robert D. “Consumer's Surplus Without Apology.” American Economic Review 66 No. 4 (September, 1976): 589-97.

Wilson, John D. "Optimal Public Good Provision with Limited Lump-Sum Taxation." American Economic Review 81 No. 1 (March, 1991): 153-66. Yitzhaki, Shlomo. "A Note on Optimum Taxation and Administrative Costs." American Economic Review 69 No. 3 (June, 1979): 475-80. 